\title{
Patient-Perceived Changes in the System of Values After Cancer Diagnosis
}

\author{
Elżbieta Greszta $\cdot$ Maria J. Siemińska
}

Published online: 5 March 2011

(C) The Author(s) 2011. This article is published with open access at Springerlink.com

\begin{abstract}
A cross-sectional study investigated changes in patients' value systems following a diagnosis of cancer. Fifty patients at 1 to 6 months following cancer diagnosis, were asked to compare their current values with their recollection of past values. Using the Rokeach Value Survey we obtained statistically significant results showing that twenty-seven out of thirty-six values changed their importance from the patients' perspective: 16 values significantly increased, while 11 values significantly decreased in importance. Changes with respect to nine values were insignificant. We indentified clusters of values increasing in importance the most: Religious morality (Salvation, Forgiving, Helpful, Clean), Personal orientation (Self-Respect, True Friendship, Happiness), Self-constriction (Self-Controlled, Obedient, Honest), Family security (Family Security, Responsible), and Delayed gratification (Wisdom, Inner Harmony). We also observed that the following value clusters decreased in importance: Immediate gratification (An Exciting Life, Pleasure, A Comfortable Life); Selfexpansion (Capable, Ambitious, Broadminded), Competence (A Sense of Accomplishment, Imaginative, Intellectual). The remaining values belonged to clusters that as a group changed slightly or not at all. Practical implications of the study are discussed.
\end{abstract}

Keywords Cancer patients - Cancer diagnosis . Value system $\cdot$ Value change

E. Greszta $(\square)$

Helena Chodkowska University of Management and Law,

Warsaw, Poland

e-mail: ela.greszta@gmail.com

M. J. Siemińska

International Hereditary Cancer Center, Szczecin, Poland

\section{Introduction}

This paper focuses on patient perceived shifts in value priorities after severe changes in life quality in general and a life-threatening cancer diagnosis in particular. As one would expect cancer diagnosis is likely the most stressful and alarming news for patients. It brings shock, uncertainty and emotional reactions such as fear, insecurity, sadness, anger, guilt, feelings of loneliness, helplessness and hopelessness (e.g., Watson et al., 1999). It is a traumatic experience and there is substantial literature documenting cancer-related PTSD symptoms (see review by Kangas, Henry, \& Bryant 2002).

Cancer patients face many threats to psychological wellbeing. They worry about their families, feel uncertain about the future and have to face their own mortality (Deadman, Dewey, Owens, Leinster, \& Slade, 1989). They also have to cope with the emotional responses of concerned friends and loved ones who may experience a range of emotions including fear and a desire to take charge (Roos, 2003). Moreover, cancer patients experience or anticipate many negative changes with respect to their career (employment), family (shifting roles within the family), social life, body image (fear of disfigurement), interpersonal relations, deterioration of cognitive and physical abilities, and selfesteem (e.g., Hopwood \& Stephens, 2000; Ramsey et al., 2000).

Surprisingly, in spite of great distress and anxiety brought about by cancer diagnosis, many cancer patients view certain aspects of their experience as positive or beneficial. There are countless examples of such attitudes in the literature, and a few are quoted below. Some cancer patients report improvement in personal resources, sense of purpose, spirituality, closer interpersonal relations and changes in life priorities (Carver \& Antoni, 2004; Fromm, 
Andrykowski, \& Hunt, 1996). Some even positively relate event severity to experienced benefits, suggesting that the more severe the event the greater the potential for personal growth and transformation (McMillen, Smith, \& Fisher, 1997). Many cancer survivors attribute positive changes in attitude to having had cancer, including developing a new outlook on life and greater appreciation for life (Fromm et al. 1996; Salmon, Manzi, \& Valori, 1996). In one retrospective study, the majority of cancer survivors reported that their marital relationships had improved since the cancer episode (Lichtman, Taylor, \& Wood, 1987). According to Tempelaar et al. (1989) cancer patients reported more positive and fewer negative social experiences than a group of healthy controls. Collins, Taylor, and Skokan (1990) followed cancer patients for 5 years after diagnosis (or recurrence) and observed significant positive changes in their interpersonal relations as well as in their self-image. Research of Andrykowski, Brady, and Hunt (1993) showed that cancer patients' outlook on life and their interpersonal relations improved and they derived greater satisfaction from religious life.

Thornton (2002) examined benefit-construal following cancer diagnosis and presented a simple framework to organize qualitative and quantitative data from literatures. She identified three areas in which cancer survivors frequently report deriving benefits: life perspective, interpersonal relationships, and the self. Belec (1992) showed that as many as $90 \%$ of bone marrow transplant survivors associated the cancer experience with a (positive) reassessment of their priorities and values in life. Andrykowski et al. (1993) and Arman and Rehnsfeldt (2003) have emphasized the role of changing value systems in the process of fighting cancer. They claim that acceptance of a cancer diagnosis is often seen as a psychosocial transition, which leads individuals to restructure their values. Authors of the present study, when doing volunteer work with cancer patients, have often heard spontaneous statements, such as: "My system of values has changed", "My life priorities are different now".

There have been attempts to explain the phenomenon of perceived value change in the aftermath of cancer diagnosis from the perspective of existential theory (see Cordova et al. 2007) which postulates that the state of a disequilibrium experienced when faced with mortality may provide an opportunity for reconsideration of fundamental life values. Janoff-Bulman (2004) has emphasized the potential for trauma to "shatter assumptions" individuals hold about themselves, the future, and the world.

Theories of coping and adjustment to adversity and crisis postulate that individuals hold fundamentally positive, adaptive assumptions about the world and their place in it. They believe that life is meaningful, ordered, purposeful, view the self as worthy, and consider the world to be essentially just and predictable (see Thornton, 2002). When such beliefs are challenged or disrupted by sufficiently traumatic or stressful events, the victim strives to rebuild this assumptive world (Janoff-Bulman, 1989). To sum up, patient-perceived changes in value systems following cancer diagnosis are evident from theoretical deliberations, qualitative research, case studies and clinical observations, but there is very little empirical data on this subject.

A conceptual framework for this study was derived primarily from the Rokeach theory of value and value change. We used the Rokeach Value Survey (RVS) to measure patient-perceived changes in the value systems. For Rokeach $(1973$, p. 5) a value is "an enduring belief that a specific mode of conduct or end-state of existence is personally or socially preferable to an opposite or converse mode of conduct or end-state of existence". Consequently Rokeach differentiates between the end-states, which correspond to terminal values and the modes-of conduct, which represent values instrumental to attain the desired end states (instrumental values). This led Rokeach to divide 36 values into two sets (instrumental and terminal values) with 18 ranked values in each set. Thus Rokeach developed a measuring tool called the Rokeach Value Survey, RVS, which was used in our study.

Some authors consider Rokeach's distinction between terminal and instrumental values to be arbitrary, unjustified conceptually and not confirmed by survey respondents who do not spontaneously differentiate between terminal and instrumental values (e.g.: Heath \& Fogel, 1978; Jones, Sensenig, \& Ashmore, 1978). In their view such distinction does not clarify meaningful differences in individual value systems. Others however argue for the importance of Rokeach's distinction and provide empirical support for such categorization (among other Braithwaite \& Law, 1985; Feather, 1986; Feather \& Peay, 1975; Rokeach, 1973; Schwartz \& Bilsky, 1987). The distinction between terminal and instrumental values was maintained in recent studies (e.g., Murphy, Gordon, \& Mullen, 2004; Musil, Rus, \& Musek, 2009) and has been used in our study, although it is not the focus of our work.

Rokeach considers values to be relatively stable (Rokeach \& Ball-Rokeach, 1989), but factors such as life experiences, new roles and responsibilities may change the importance of particular values. Therefore, it seems that to satisfy one's needs in conditions changed by illness, changes within the value system must take place. The intensity of changes corresponds to the importance of threatened values. Rokeach $(1973,1979)$ found that values could change rapidly because of: (1) significant socialization; (2) self-confrontation; (3) significant emotional events, or (4) cultural upheaval. Undoubtedly cancer diagnosis is a significant, often traumatic emotional event. Cancer diagnosis 
could also be viewed as "self-confrontation" when people face their own mortality and other serious threats and losses. Cancer diagnosis brings "cultural upheaval" as patients anticipate impairments in competition, efficiency and ability, expect negative changes of their body image while living in a culture that favours intelligence, work, creativity, physical perfection and beauty.

Rokeach found that change of one or two very significant values led to multiple changes in the importance assigned to other values. Therefore we put forward a hypothesis that changes of entire clusters of values, not just individual values, occur following cancer diagnosis. We expect related values grouped in certain clusters to become more important, while we expect other clusters to decrease in importance.

Values measured using the RVS questionnaire can be grouped into the seven bipolar clusters (e.g., Immediate gratification vs. Delayed gratification, Competence vs. Religious morality, Self-constriction vs. Self-expansion, etc.). Rokeach (1973) says that attitudes and behaviours are rooted in our value structures. Also, Feather (1995) postulates that underlying our behaviour are attitudes and underlying these attitudes are values. Therefore, in our anticipation of results, we were guided by results of studies on changes in behaviour and attitudes of patients after a diagnosis of cancer. As described above, cancer survivors reported changes in such areas as life perspective, interpersonal relationships, and the self. They valued life more, devoted more time to inner development (were more aware of self, and their needs), spent more time with their families, become more religious etc. Therefore we expect the following clusters of values to increase in importance: Delayed gratification, Religious morality, Personal orientation, Respect, Love, Inner Directed; and we expect clusters such as Immediate gratification to decrease in value.

Finally we would like to refer to a study of a different type of life-threatening event and the related changes in values which occurred in the United States in the aftermath of the September 11, 2001 terrorist attack on the World Trade Center in New York (Murphy et al., 2004). We suspect that cancer patients might, like aviation industry employees after the attack, value clusters such as Family security more, while ascribing less value to clusters such as Immediate gratification, Delayed gratification and Selfexpansion. However we also expect to see differences. A terrorist attack poses a similar threat to life as cancer, but it comes from a different source. Therefore we do not expect patients after diagnosis of cancer to assign increased value to clusters such as Societal security, Social orientation (National Security, A World at Peace, etc.) and Inner directed (Courageous), as was the case for the aviation industry employees after the attack (Murphy et al., 2004).
In summary we expect patients after a diagnosis of cancer to: (1) assign higher importance to values from the following clusters: Religious morality, Self-constriction, Personal orientation, Family security, Respect, Love; (2) assign lower importance to values from the following clusters: Immediate gratification, Delayed gratification, Competence, Self-expansion; (3) assign lower or the same (pre-diagnosis) importance to values from the following clusters: Social orientation, Societal security.

\section{Method}

\section{Participants}

Participants were 50 hospitalized patients at 1-6 months following first diagnosis of cancer. In order not to detect transient changes or changes which could be attributed to the trauma triggered by the diagnosis we decided that a minimum time elapsing since the cancer diagnosis had to be 1 month. At the same time it seemed that if more than 6 months passed from diagnosis it could be difficult for patients to retrospectively evaluate their value systems (priorities) prior to diagnosis. The patients had not been offered any psychological counselling following cancer diagnosis.

The recruitment procedure took over 3 months. We identified every tenth patient out of all patients admitted into cancer wards of three hospitals located in a city of 400,000 residents (providing care for patients from a large northern region of Poland), who were first diagnosed with cancer 1-6 months earlier. Thirty percent of the approached group (22 persons) refused to participate in our study, justifying their decision with not feeling well or not remembering the time before the illness. Some patients did not give an explanation for their refusal. As a result, our sample consisted of 50 patients.

The obtained sample corresponded closely to a representative sample of the cancer patients' population in Poland in terms of age and education but differed quite significantly with respect to sex and cancer type. According to the National Cancer Registry (in: Wojciechowska, Didkowska, \& Zatoński, 2008) first time malignant tumours are reported in Poland almost at the same level for men as women (71,000 and 68,000, respectively). In our sample there were significantly more men than women (1.4:1). Among the general population of cancer patients in Poland the most common types of cancer for men are pulmonary carcinoma $(23 \%)$ and prostatic carcinoma $(11 \%)$ while for women-mammary carcinoma (21\%) and pulmonary carcinoma $(8 \%)$. In our sample pulmonary carcinoma was not present at all, while mammary carcinoma was underrepresented. Proportions of other carcinomas were similar to 
those in the general population of cancer patients. Participants in our study suffered from the following types of cancer (in parenthesis the number of patients with each cancer type): gastric carcinoma (8), colorectal carcinoma (8), cervical carcinoma (6), prostatic carcinoma (6), endometrial carcinoma (5), mammary cancer (3), melanoma (3), ovarian carcinoma (2), bladder cancer (2), renal carcinoma (2), pancreas cancer (1), gallbladder cancer (1) and lymphomas (3).

There were 21 women and 29 men among the subjects; ranging in age from 34 to $79(\mathrm{M}=56.2$ years, $\mathrm{SD}=9.6)$. Our sample consisted of 9 people who only finished elementary school, 15 people with vocational education, 21 people with high school education, and 5 people with a university degree.

\section{Measure}

The Rokeach Value Survey (RVS) was developed by Rokeach (1973) to measure relative importance of values within two systems of values, terminal and instrumental. The RVS consists of two alphabetic lists, with each list consisting of 18 values, one list for terminal values and one for instrumental values. The subject's task is to rank the values within each list in their order of importance. The RVS remains a popular tool for assessment of structured values (Keany \& Glueckauf, 1993; Murphy et al., 2004) despite the fact that the heyday of RVS research was some years ago. The RVS is recommended as the right tool to measure value changes in health research (Keany \& Glueckauf, 1993) and is considered suitable for preliminary research on value changes. Another reason for selecting the RVS was its relative shortness and simplicity in the original language version and consequently the availability of a reliable and comprehensible Polish translation. Last, but not least, the Rokeach Value Survey has one important quality: it is easy to complete even for less educated people.

The construct and predictive validity of the RVS has also been documented across a wide variety of populations and settings (Johnston, 1995) and this survey has been used successfully in a variety of studies (Feather, 1986). Based on their most recent research results, Musil et al. (2009) reached the conclusion that despite some conceptual shortcomings, the RVS still shows relevance for value research.

To examine changes in patients' value systems we used the Polish version of the Rokeach Value Survey (Brzozowski 1989, 1996). The Polish version of the RVS has been translated from the most often used form of RVS called the E Value Survey. Creating the Polish version of the RVS, Brzozowski (1989) tried to maintain all the characteristic features of the original (two subscales with
18 entries each, etc.). Comparability between the English original and the Polish adaptation of the RVS has been checked by Brzozowski (1989). The rank correlation coefficient (Rho) between the Polish and the English scale of terminal and instrumental values was .99 and .98, respectively. The average Pearson correlation coefficient $r$ for each of the 18 terminal and 18 instrumental values was .79 and .68 , respectively.

The test-retest reliability of the English language version of the RVS was found to be .74 for the terminal values subscale and .65 for the instrumental values subscale (Rokeach, 1973). In other studies, these values were similar and equalled .73 and .72, respectively (Cooper \& Clare, 1981). The reliability of each item of the RVS was on average .65 for terminal values and .60 for instrumental values (Rokeach, 1973). The test-retest reliability of the Polish adaptation of the RVS was .95 and .91 for the two subscales, respectively. The average reliability for each of the 18 terminal and 18 instrumental values, considered separately, equalled .66 and .57, respectively (Brzozowski, 1989).

Our subjects received two separate sheets with lists of values. The left-most column of Table 1 shows the alphabetically ordered list of terminal values exactly as the subjects would see them. Next to each value in the list, responders would write in the numerical rank that they would assign to that value. Similarly, the left-most column of Table 2 shows the alphabetically ordered list of instrumental values. Responders were asked to rank them just like in the case of terminal values. As with the English version of the RVS, the Polish version includes short, parenthetical phrases that describe and clarify each value (as seen in Tables 1,2). Respondents arranged all values from each list from most to least important (separately for terminal and instrumental values). They were instructed to insert " 1 " next to the value they considered most important, a "2" for the second most important value, and so on, until the least important values received the number 18 .

\section{Procedure}

Our study ${ }^{1}$ was designed to compare cancer patients' retrospective ratings of their values before and after cancer diagnosis. This was achieved by having the participants complete the RVS questionnaire twice. First they ranked terminal values and instrumental values by answering the following question: "Which values are the most and the least important to you now? What is your present hierarchy

\footnotetext{
${ }^{1}$ The Research Committee of the Warsaw School of Social Psychology granted permission for the study. Ethical approval of the study was obtained from the head of each hospital's departments of the participants.
} 
Table 1 Differences in mean ranking of terminal values in two settings: past focus (prior to cancer diagnosis) and present focus (following cancer diagnosis) (paired sample two-tailed $t$-test; $N=50$ )

\begin{tabular}{|c|c|c|c|c|c|}
\hline \multirow[t]{2}{*}{ Terminal values } & \multicolumn{2}{|l|}{ Past focus } & \multicolumn{2}{|c|}{ Present focus } & \multirow{2}{*}{$\begin{array}{l}\text { Significance } \\
\text { (2-tailed } p \text { ) }\end{array}$} \\
\hline & Mean rank & SD & Mean rank & SD & \\
\hline A comfortable life (a prosperous life) & 6.08 & 5.79 & 11.78 & 5.85 & $.000 * * *$ \\
\hline An exciting life (a stimulating, active life) & 6.86 & 5.94 & 13.66 & 4.74 & $.000 * * *$ \\
\hline A sense of accomplishment (lasting contribution) & 7.08 & 5.11 & 10.18 & 4.46 & $.000 * * *$ \\
\hline A world at peace (free of war and conflict) & 9.60 & 5.02 & 9.42 & 4.74 & .780 \\
\hline A world of beauty (beauty of nature and the arts) & 11.32 & 4.25 & 10.26 & 4.10 & .135 \\
\hline Equality (brotherhood, equal opportunity for all) & 10.80 & 3.82 & 11.78 & 4.44 & .163 \\
\hline Family security (taking care of loved ones) & 10.04 & 6.36 & 5.44 & 4.37 & $.000 * * *$ \\
\hline Happiness (contentedness) & 7.00 & 3.91 & 5.64 & 3.99 & $.041 *$ \\
\hline Freedom (independence, free choice) & 8.16 & 4.15 & 9.06 & 4.76 & .296 \\
\hline Inner harmony (freedom from inner conflict) & 12.90 & 4.71 & 10.64 & 3.84 & $.006^{* *}$ \\
\hline Mature love (sexual and spiritual intimacy) & 9.08 & 4.61 & 10.10 & 5.00 & .243 \\
\hline National security (protection from attack) & 10.22 & 4.84 & 11.34 & 4.25 & $.033 *$ \\
\hline Pleasure (an enjoyable, leisurely life) & 8.34 & 5.50 & 13.20 & 3.88 & $.000 * * *$ \\
\hline Salvation (saved, eternal life) & 13.40 & 5.02 & 8.68 & 6.26 & $.000 * * *$ \\
\hline Self-respect (self-esteem) & 10.64 & 4.35 & 5.94 & 4.61 & $.000 * * *$ \\
\hline Social recognition (respect, admiration) & 9.28 & 4.95 & 10.42 & 4.20 & .206 \\
\hline True friendship (close companionship) & 9.22 & 3.91 & 6.82 & 4.70 & $.004 * *$ \\
\hline Wisdom (a mature understanding of life) & 10.98 & 4.01 & 6.64 & 4.18 & $.000 * * *$ \\
\hline
\end{tabular}

Note: A decrease in the score means a value has become more important to the subject, i.e., it has a relatively higher position in patient hierarchy of values. An increase in score means a value has become less important to the subject, i.e., it has a relatively lower position in patient's hierarchy of values. * $p<.05 ; * * p<.01 ; * * * p<.001$

of values?" Next they were asked to rank the same terminal and instrumental values but reflecting on the time before they were diagnosed with cancer: "Which values were the most and the least important to you before the diagnosis? What was your hierarchy of values prior to your illness?" A similar procedure has been used in other studies, e.g., the 'now-test' and the 'then-test' procedure in Sharpley and Christie (2007).

\section{Results}

In order to analyze the shifts in values, mean ranks were computed for each value and placed in a table. The authors evaluated their hypotheses for statistical significance with standard t-test for dependent samples with $p<.05$ as the level of significance, the standard level used in sociological research using the Rokeach Value Survey (RVS). As shown in Tables 1 and 2 patients reported twelve statistically significant terminal value differences and fifteen instrumental value differences after cancer diagnosis. Tables 3, 4 and 5 presented below show values that became more important, less important and did not change, respectively. In those tables values are grouped in clusters which will be the focus of discussion in the last section of the paper.

\section{Values that Became More Important}

Table 3 shows terminal and instrumental values that became significantly more important after diagnosis from the patient's point of view. It shows the mean ranking for each value before cancer diagnosis (in retrospect) and in the current value system (1-6 months after diagnosis). Seven terminal and nine instrumental values became significantly more important. The following six terminal values strongly increased in importance: Family Security from a mean rank of 10.04 and lower position in the hierarchy of values to 5.44 and higher position within value hierarchy; Salvation from a mean rank of 13.40-8.68; SelfRespect from a mean rank of 10.64 to a mean rank of 5.94; Wisdom from a mean rank of 10.98-6.64 $(p<.0005)$; True Friendship from a mean rank of 9.22-6.82 $(p<.005)$ and Inner Harmony from a mean rank of 12.90-10.64 $(p<.01)$. The following three instrumental values strongly increased in importance: Forgiving moved from a mean rank of 12.14-6.86; Obedient from a mean rank of 
Table 2 Differences in mean rankings of instrumental values in two settings: past focus (prior to cancer diagnosis) and present focus (following cancer diagnosis) (paired sample two-tailed $t$-test; $N=50$ )

\begin{tabular}{|c|c|c|c|c|c|}
\hline \multirow[t]{2}{*}{ Instrumental values } & \multicolumn{2}{|l|}{ Past focus } & \multicolumn{2}{|c|}{ Present focus } & \multirow{2}{*}{$\begin{array}{l}\text { Significance } \\
(2 \text {-tailed } p)\end{array}$} \\
\hline & Mean rank & SD & Mean rank & SD & \\
\hline Ambitious (hard-working, aspiring) & 8.84 & 7.10 & 15.08 & 5.07 & $.000 * * *$ \\
\hline Broadminded (open-minded) & 8.12 & 5.37 & 11.98 & 4.40 & $.000 * * *$ \\
\hline Capable (competent, effective) & 7.88 & 5.81 & 13.96 & 4.61 & $.000 * * *$ \\
\hline Cheerful (lighthearted, joyful) & 6.62 & 4.11 & 7.74 & 5.05 & .096 \\
\hline Clean (neat, tidy) & 9.16 & 5.11 & 6.92 & 4.85 & $.017 *$ \\
\hline Courageous (standing up for your beliefs) & 7.36 & 4.70 & 9.10 & 3.96 & $.021 *$ \\
\hline Forgiving (willing to pardon others) & 12.14 & 4.99 & 6.86 & 4.33 & $.000 * * *$ \\
\hline Helpful (working for the welfare of others) & 10.90 & 5.44 & 8.36 & 4.96 & $.008^{*}$ \\
\hline Honest (sincere, truthful) & 8.72 & 4.09 & 7.02 & 4.01 & $.032 *$ \\
\hline Imaginative (daring, creative) & 9.46 & 4.88 & 12.90 & 4.95 & $.002 * *$ \\
\hline Independent (self-reliant, self-sufficient) & 7.46 & 5.04 & 5.32 & 4.42 & $.018^{*}$ \\
\hline Intellectual (intelligent, reflective) & 10.44 & 4.74 & 11.82 & 3.39 & $.041 *$ \\
\hline Logical (consistent, rational) & 10.04 & 4.57 & 10.22 & 5.19 & .817 \\
\hline Loving (affectionate, tender) & 9.80 & 4.74 & 7.64 & 4.74 & $.017 *$ \\
\hline Obedient (dutiful, respectful) & 11.48 & 4.43 & 8.66 & 3.77 & $.000 * * *$ \\
\hline Polite (courteous, well-mannered) & 10.26 & 4.70 & 10.36 & 4.09 & .892 \\
\hline Responsible (dependable, reliable) & 9.26 & 3.94 & 7.36 & 4.12 & $.008^{*}$ \\
\hline Self-controlled (restrained, self-disciplined) & 13.06 & 4.63 & 9.70 & 4.82 & $.000 * * *$ \\
\hline
\end{tabular}

Note: A decrease in the score means a value has become more important to the subject, i.e., it has a relatively higher position in patient's hierarchy of values. An increase in score means a value has become less important to the subject, i.e., it has a relatively lower position in patient's hierarchy of values. $* p<.05 ; * * p<.01 ; * * * p<.001$

11.48-8.66 and Self-Controlled from a mean rank of 13.06-9.70 $(p<.0005)$. One terminal and the following six instrumental values slightly increased in importance: Happiness, and Clean, Helpful, Honest, Independent, Loving and Responsible ( $p<.05$ in all cases).

Values that Became Less Important

Table 4 shows terminal and instrumental values that became significantly less important from the patient's point of view after cancer diagnosis. It shows the mean ranking for each value before cancer diagnosis (in retrospect) and in the current value system (1-6 months after diagnosis). Five terminal and six instrumental values became significantly less important. Four terminal and four instrumental values strongly decreased in importance. The following terminal values moved from higher to lower place in patients' value systems: A Comfortable Life from a mean rank of 6.08-11.78; An Exciting Life from a mean rank of 6.86-13.66; A Sense of Accomplishment from a mean rank of 7.08-10.18 and Pleasure from a mean rank of 8.34-13.20 $(p<.0005)$. The following instrumental values moved down in the value system as perceived by patients: Ambitious from a mean rank of 8.84-15.08; Broadminded from a mean rank of 8.12-11.98; Capable from a mean rank of 7.88-13.96 $(p<.0005)$; Imaginative from a mean rank 9.46-12.90 $(p<.005)$. One terminal and two instrumental values slightly decreased in importance: National Security, Courageous and Intellectual $(p<.05)$.

Values that did not Change

Table 5 shows terminal and instrumental values that did not change significantly. It shows the mean ranking for each value before cancer diagnosis (in retrospect) and in the current value system (1-6 months after diagnosis). An insignificant change in importance was registered for the following six terminal values: A World of Beauty, Equality, Social Recognition, Mature Love, Freedom and A World at Peace. An insignificant change in importance was observed for the following three instrumental values: Cheerful, Logical, and Polite.

\section{Discussion}

Our results confirmed the assumptions made on the basis of qualitative studies, theoretical discussion and clinical observation that from the patient's point of view the system or hierarchy of values changes following cancer diagnosis. 
Table 3 Values that became more important

\begin{tabular}{|c|c|c|c|}
\hline & $\begin{array}{l}\text { Past focus } \\
\text { Mean rank }\end{array}$ & $\begin{array}{l}\text { Present focus } \\
\text { Mean rank }\end{array}$ & $\begin{array}{l}\text { Significance } \\
(2 \text {-tailed } p)\end{array}$ \\
\hline \multicolumn{4}{|l|}{ Terminal values } \\
\hline \multicolumn{4}{|c|}{ Personal orientation } \\
\hline Self-respect & 10.64 & 5.94 & $.000 * * *$ \\
\hline True friendship & 9.22 & 6.82 & $.004 * *$ \\
\hline Happiness & 7.00 & 5.64 & $.041 *$ \\
\hline \multicolumn{4}{|l|}{ Religious morality } \\
\hline Salvation & 13.40 & 8.68 & $.000 * * *$ \\
\hline \multicolumn{4}{|l|}{ Family security } \\
\hline Family security & 10.04 & 5.44 & $.000 * * *$ \\
\hline \multicolumn{4}{|c|}{ Delayed gratification } \\
\hline Wisdom & 10.98 & 6.64 & $.000 * * *$ \\
\hline Inner harmony & 12.90 & 10.64 & $.006 * *$ \\
\hline \multicolumn{4}{|c|}{ Instrumental values } \\
\hline \multicolumn{4}{|l|}{ Religious morality } \\
\hline Forgiving & 12.14 & 6.86 & $.000 * * *$ \\
\hline Helpful & 10.90 & 8.36 & $.008^{*}$ \\
\hline Clean & 9.16 & 6.92 & $.017 *$ \\
\hline \multicolumn{4}{|l|}{ Self-constriction } \\
\hline Self-controlled & 13.06 & 9.70 & $.000 * * *$ \\
\hline Obedient & 11.48 & 8.66 & $.000 * * *$ \\
\hline Honest & 8.72 & 7.02 & $.032 *$ \\
\hline \multicolumn{4}{|l|}{ Family security } \\
\hline Responsible & 9.26 & 7.36 & $.008 *$ \\
\hline \multicolumn{4}{|l|}{ Love } \\
\hline Loving & 9.80 & 7.64 & $.017 *$ \\
\hline \multicolumn{4}{|l|}{ Inner directed } \\
\hline Independent & 7.46 & 5.32 & $.018^{*}$ \\
\hline
\end{tabular}

Note: $* p<.05 ; * * p<.01 ; * * * p<.001$

We found twelve statistically significant terminal value differences and fifteen instrumental value differences. Out of the 36 investigated values patients reported statistically significant increase in importance for 16 values ( 7 terminal and 9 instrumental) and statistically significant decrease in importance for 11 values ( 5 terminal and 6 instrumental). Nine values shifted insignificantly (6 terminal and 3 instrumental).

Factor analysis of the RVS questionnaire conducted by Rokeach (1973, p. 47) revealed seven bipolar factors: (I) Immediate gratification (A Comfortable Life, Pleasure, An Exciting Life, Clean) vs. Delayed gratification (Logical, Wisdom, Inner Harmony, Self-Controlled); (II) Competence (Logical, Imaginative, Intellectual, Independent) vs. Religious morality (Forgiving, Salvation, Helpful, Clean); (III) Self-constriction (Obedient, Polite, Self-Controlled, Honest) vs. Self-expansion (Broadminded, Capable); (IV) Social orientation (A World at Peace, Equality, National Security, Freedom) vs. Personal orientation (True
Table 4 Values that became less important

\begin{tabular}{|c|c|c|c|}
\hline & $\begin{array}{l}\text { Past } \\
\text { focus } \\
\text { Mean rank }\end{array}$ & $\begin{array}{l}\text { Present } \\
\text { focus } \\
\text { Mean rank }\end{array}$ & $\begin{array}{l}\text { Significance } \\
\text { (2-tailed } p \text { ) }\end{array}$ \\
\hline \multicolumn{4}{|l|}{ Terminal values } \\
\hline \multicolumn{4}{|l|}{ Immediate gratification } \\
\hline An exciting Life & 6.86 & 13.66 & $.000 * * *$ \\
\hline Pleasure & 8.34 & 13.20 & $.000 * * *$ \\
\hline A comfortable Life & 6.08 & 11.78 & $.000 * * *$ \\
\hline \multicolumn{4}{|l|}{ Competence } \\
\hline A sense of accomplishment & 7.08 & 10.18 & $.000 * * *$ \\
\hline \multicolumn{4}{|l|}{ Social orientation } \\
\hline National security & 10.22 & 11.34 & $.033 *$ \\
\hline \multicolumn{4}{|l|}{ Instrumental values } \\
\hline \multicolumn{4}{|l|}{ Self-expansion } \\
\hline Capable & 7.88 & 13.96 & $.000 * * *$ \\
\hline Ambitious & 8.84 & 15.08 & $.000 * * *$ \\
\hline Broadminded & 8.12 & 11.98 & $.000 * * *$ \\
\hline \multicolumn{4}{|l|}{ Competence } \\
\hline Imaginative & 9.46 & 12.90 & $.002 * *$ \\
\hline Intellectual & 10.44 & 11.82 & $.041 *$ \\
\hline \multicolumn{4}{|l|}{ Inner directed } \\
\hline Courageous & 7.36 & 9.10 & $.021 *$ \\
\hline
\end{tabular}

Note: $* p<.05 ; * * p<.01 ; * * * p<.001$

Table 5 Values that did not change

\begin{tabular}{|c|c|c|c|}
\hline & $\begin{array}{l}\text { Past focus } \\
\text { Mean rank }\end{array}$ & $\begin{array}{l}\text { Present focus } \\
\text { Mean rank }\end{array}$ & $\begin{array}{l}\text { Significance } \\
(2 \text {-tailed } p)\end{array}$ \\
\hline \multicolumn{4}{|l|}{ Terminal values } \\
\hline \multicolumn{4}{|l|}{ Social orientation } \\
\hline A world at peace & 9.60 & 9.42 & .780 \\
\hline A world of beauty & 11.32 & 10.26 & .135 \\
\hline Equality & 10.80 & 11.78 & .163 \\
\hline Freedom & 8.16 & 9.06 & .296 \\
\hline \multicolumn{4}{|l|}{ Love } \\
\hline Mature love & 9.08 & 10.10 & .243 \\
\hline \multicolumn{4}{|l|}{ Respect } \\
\hline Social recognition & 9.28 & 10.42 & .206 \\
\hline \multicolumn{4}{|l|}{ Instrumental values } \\
\hline \multicolumn{4}{|c|}{ Immediate gratification } \\
\hline Cheerful & 6.62 & 7.74 & .096 \\
\hline \multicolumn{4}{|l|}{ Competence } \\
\hline Logical & 10.04 & 10.22 & .817 \\
\hline \multicolumn{4}{|l|}{ Other directed } \\
\hline Polite & 10.26 & 10.36 & .892 \\
\hline
\end{tabular}

Friendship, Self-Respect); (V) Societal security (A World of Beauty, Equality, Helpful, Imaginative) vs. Family security (Family Security, Ambitious, Responsible, Capable) (VI) Respect (Social Recognition, Self-Respect) vs. Love (Mature Love, Loving); (VII) Other directed (Polite) 
vs. Inner directed (Courageous, Independent). An analysis of the observed results with reference to the above seven factors, showed that values which increased in importance for patients came from the following groups Religious morality, Personal orientation, Self-constriction, Family security, Delayed gratification, Love and Inner directed. The strongest growth was reported for the following single terminal values: Family Security, Salvation, Self-Respect and Wisdom and for the following instrumental values: Forgiving, Obedient and Self-Controlled.

Numerous values from the following groups decreased in importance: Immediate gratification, Self-expansion and Competence. Two more values, one from the group Social orientation and one from Inner directed decreased in importance. The strongest decline was recorded for the following single terminal values: A Comfortable Life, An Exciting Life, A Sense of Accomplishment, and Pleasure. Among the instrumental values the following decreased in value the most: Ambitious, Broadminded, Capable and Imaginative. An insignificant change in importance was mostly observed for values grouped under Social orientation (A World at Peace, A World of Beauty, Equality, Freedom). Some values from the following groups also demonstrated no significant change: Love, Respect, Immediate gratification, Competence and Other directed.

In our research design, subjects performed the same task (completing the RVS) under two different instructional sets, i.e., in response to two different questions, first focusing on the present and then on the past. This reversed order of questioning was important for patients not to focus on the process of change before they had already ranked their current values. At the same time as a result of taking part in the study patients may have become more aware of shifting importance for certain values.

Analysis of the results with reference to the seven bipolar factors shows almost a complete about-face in patient-perceived importance of values: strong decrease of Immediate gratification vs. growing importance of Delayed gratification; strong decrease of Competence vs. strong increase of Religious morality; strong increase of Selfconstriction vs. strong decrease of Self-expansion; no changes or insignificant decrease of Social orientation vs. strong increase of Personal orientation; no changes in Societal security vs. growing importance of Family security; no changes in Respect vs. slight increase in importance of Love; and insignificant change in Other-directed vs. slight growth/slight increase in importance of Innerdirected. These results confirm our hypothesis.

Our results show interesting links between instrumental and terminal values. Two value clusters: Religious morality and Family security have consequently increased in importance with respect to instrumental as well as terminal values, which likely implies that changes in those values areas are consistent and solidly anchored in respondents' value hierarchies. At the same time Personal orientation and Delayed gratification (terminal values) are likely obtained through Self-constriction, Love and Inner directed (instrumental values as means to obtain terminal goals). Decreased importance of the Competence cluster is consistent throughout terminal as well as instrumental values. Lower ratings of values from the Immediate gratification cluster are likely a result of limited importance of Selfexpansion and Inner directed.

Presented results demonstrate that being diagnosed with a life threatening disease stimulates patient perceived changes in the hierarchy of values by increasing or decreasing the importance of individual values. Given the preliminary nature of this study, we can only speculate on the mechanism and significance of the observed changes. It is reasonable to assume that goals which remain possible to pursue despite the illness, such as moral and spiritual values, become more important. Similarly, values which alleviate suffering, counter threats, or satisfy needs increase in importance in illness. We also suggest that patients start to prefer those values which facilitate adaptation to the threat of cancer (Delayed gratification, Religious morality, Self-constriction, Personal orientation, Family security). Values which become less important in the face of cancer diagnosis correspond to values which become difficult to accomplish in illness (Immediate gratification, Competence, Self-expansion).

We strongly believe that research in the area of values is likely to produce results which could be applied to help patients cope successfully with the stress of receiving a cancer diagnosis and help them experience positive outcomes. Understanding positive adjustment to cancer is important for improving patients' quality of life. Evaluating patient-perceived changes in values could also lead to development of efficient counselling methods, since values may also be considered not only as generalized beliefs about what is or is not desirable but also as motivating factors. Values affect patients' effort, persistence, choices between alternative activities, the way situations are construed, and affective responses to successfully or unsuccessfully undertaking activities in terms of the standards that are set (Feather, 1995).

There are important limitations to this study. Participants were volunteers as in most studies conducted in psycho-oncology. Our study was retrospective in nature and there was no control group which precludes a strong interpretation of our results. We are aware that the basic design of our study was cross-sectional while prospective studies constitute the real challenge in psycho-oncology. Moreover additional studies would be needed to confirm our results. Nevertheless our study provides significant insights into the question of value changes following cancer diagnosis. What is needed however, are prospective and 
longitudinal studies to investigate the dynamics of those changes. Are these changes in values permanent or ephemeral? Are they unique to cancer experience? Several directions could be identified for further research. Individual areas impacted by cancer should be correlated with changes in patients' systems of values. Patients' personal problems (family, professional), existential problems (confronting own mortality) and successful or unsuccessful coping, as well as positive and negative outcomes of the illness (emotional reactions, psychological distress, mental disorders) should be examined from the perspective of the system of values. Such an integrated approach could facilitate the development of a more beneficial and holistic approach to the care of cancer patients.

Acknowledgments The authors wish to thank all patients who participated in this study.

Open Access This article is distributed under the terms of the Creative Commons Attribution Noncommercial License which permits any noncommercial use, distribution, and reproduction in any medium, provided the original author(s) and source are credited.

\section{References}

Andrykowski, M. A., Brady, M. J., \& Hunt, J. W. (1993). Positive psychosocial adjustment in potential bone marrow transplant recipients: Cancer as a psychosocial transition. Psycho-Oncology, 2, 261-276.

Arman, M., \& Rehnsfeldt, A. (2003). The hidden suffering among breast cancer patients: A qualitative metasynthesis. Qualitative Health Research, 13, 510-527.

Belec, R. H. (1992). Quality of life: Perceptions of long-term survivors of bone marrow transplantation. Oncology Nursing Forum, 19, 31-37.

Braithwaite, V. A., \& Law, H. G. (1985). Structure of human values: Testing the adequacy of the Rokeach Value Survey. Journal of Personality and Social Psychology, 49, 250-263.

Brzozowski, P. (1989). Skala Wartości-polska wersja testu Miltona Rokeacha. In R. Ł. Drwal (Ed.), Techniki kwestionariuszowe w diagnostyce psychologicznej: wybrane zagadnienia (2nd ed., pp. 81-122). Lublin: UMCS.

Brzozowski, P. (1996). Skala Wartoś́i (SW), polska adaptacja value survey M. Rokeacha. Warszawa: Pracownia Testów Psychologicznych PTP.

Carver, C. S., \& Antoni, M. H. (2004). Finding benefit in breast cancer during the year after diagnosis predicts better adjustment 5 to 8 years after diagnosis. Health Psychology, 26, 595-598.

Collins, R. L., Taylor, S. E., \& Skokan, L. A. (1990). A better world or a shattered vision? Changes in life perspectives following victimization. Social Cognition, 8, 263-285.

Cooper, D., \& Clare, D. (1981). A magnitude estimation scale for human values. Psychological Report, 49, 431-438.

Cordova, M. J., Giese-Davis, J., Golant, M., Kronenwetter, C., Chang, V., \& Spiegel, D. (2007). Breast cancer as trauma: Posttraumatic stress and posttraumatic growth. Journal of Clinical Psychology in Medical Settings, 14, 308-319.

Deadman, J. M., Dewey, M. J., Owens, R. G., Leinster, S. J., \& Slade, P. D. (1989). Threat and loss in breast cancer. Psychological Medicine, 19, 677-681.
Feather, N. T. (1986). Cross-cultural studies with the Rokeach values survey: The Flinders program of research on values. Australian Journal of Psychology, 38, 269-283.

Feather, N. T. (1995). Values, valences, and choice: The influence of values on the perceived attractiveness and choice of alternatives. Journal of Personality and Social Psychology, 68, 1135-1151.

Feather, N. T., \& Peay, E. R. (1975). The structure of terminal and instrumental values: Dimensions and clusters. Australian Journal of Psychology, 27, 151-164.

Fromm, K., Andrykowski, M. A., \& Hunt, J. (1996). Positive and negative psychosocial sequelae of bone marrow transplantation: Implications for quality of life assessment. Journal of Behavioral Medicine, 19, 221-240.

Heath, R. L., \& Fogel, D. S. (1978). Terminal and instrumental? An inquiry into Rokeach's value survey. Psychological Reports, 42, $1147-1154$.

Hopwood, P., \& Stephens, R. J. (2000). Depression in patients with lung cancer: Prevalence and risk factors derived from quality-oflife data. Journal of Clinical Oncology, 18, 893-903.

Janoff-Bulman, R. (1989). Assumptive worlds and the stress of traumatic events: Applications of the schema construct. Social Cognition, 7, 113-136.

Janoff-Bulman, R. (2004). Posttraumatic growth: Three explanatory models. Psychological Inquiry, 15, 30-34.

Johnston, C. S. (1995). The Rokeach value survey: Underlying structure and multidimensional scaling. Journal of Psychology, 129, 583-597.

Jones, R. A., Sensenig, J., \& Ashmore, R. D. (1978). Systems of values and their multidimensional representations. Multivariate Behavioral Research, 13, 255-270.

Kangas, M., Henry, J. L., \& Bryant, R. A. (2002). Posttraumatic stress disorder following cancer: A conceptual and empirical review. Clinical Psychology Review, 22, 499-524.

Keany, K. C., \& Glueckauf, R. L. (1993). Disability and value change: An overview and reanalysis of acceptance of loss theory. Rehabilitation Psychology, 38, 199-210.

Lichtman, R. R., Taylor, S. E., \& Wood, J. V. (1987). Social support and marital adjustment after breast cancer. Journal of Psychosocial Oncology, 5, 47-74.

McMillen, J. C., Smith, E. M., \& Fisher, R. H. (1997). Perceived benefit and mental health after three types of disaster. Journal of Consulting and Clinical Psychology, 65, 733-739.

Murphy, E. F., Jr., Gordon, J. D., \& Mullen, A. (2004). A preliminary study exploring the value changes taking place in the United States since the September 11, 2001 terrorist attack on the World Trade Center in New York. Journal of Business Ethics, 50, 81-96.

Musil, B., Rus, V. S., \& Musek, J. (2009). The Rokeach value survey in comparative study of Japanese and Slovenian students: Towards the underlying structure. Studia Psychologica, 51, 53-68.

Ramsey, S. D., Andersen, M. R., Etzioni, R., Moinpour, C., Potosky, A., \& Urban, N. (2000). Quality of life in survivors of colorectal carcinoma. Cancer, 88, 1294-1303.

Rokeach, M. (1973). The nature of human values. New York: Free Press.

Rokeach, M. (1979). Understanding human values: Individual and societal. New York: Free Press.

Rokeach, M., \& Ball-Rokeach, S. J. (1989). Stability and change in American value priorities. American Psychologist, 44, 775-784.

Roos, I. A. G. (2003). Reacting to the diagnosis of prostate cancer: Patient learning in a community of practice. Patient Education and Counseling, 49, 219-224.

Salmon, P., Manzi, F., \& Valori, R. M. (1996). Measuring the meaning of life for patients with incurable cancer: The Life Evaluation Questionnaire (LEQ). European Journal of Cancer, $32 A, 755-760$. 
Schwartz, S. H., \& Bilsky, W. (1987). Toward a universal psychological structure of human values. Journal of Personality and Social Psychology, 53, 550-562.

Sharpley, C. F., \& Christie, D. R. (2007). 'How I was then and how I am now': Current and retrospective self-reports of anxiety and depression in Australian women with breast cancer. PsychoOncology, 16, 752-762.

Tempelaar, R., de Haes, J. C. J. M., de Ruiter, J. H., Bakker, D., van den Heuvel, W. J. A., \& van Nieuwenhuijzen, M. G. (1989). The social experiences of cancer patients under treatment: A comparative study. Social Science and Medicine, 29, 635-642.
Thornton, A. A. (2002). Perceiving benefits in the cancer experience. Journal of Clinical Psychology in Medical Settings, 9, 153-165. Watson, M., Haviland, J. S., Greer, S., Davidson, J., \& Bliss, J. M. (1999). Influence of psychological response on survival in breast cancer: A population-based cohort study. Lancet, 354, 1331-1336.

Wojciechowska, U., Didkowska, J., \& Zatoński, W. (2008). Cancer in Poland in 2006. Warsaw: The Maria Sklodowska-Curie Memorial Cancer Center and Institute of Oncology. http://www. onkologia.org.pl/doc/Biuletyn2006.pdf. 